\title{
A NOTE ON DOCUMENTATION
}

\author{
AND EDITORIAL PRACTICE
}

Spelling has been modernized and punctuation regularized in all quotations from early modern texts.

Footnotes give short references only and are keyed to the Bibliography, where complete publication information is provided. For works from the early modern period, place of publication is London except when otherwise noted.

For the reader's convenience I refer to modern editions of Renaissance texts whenever possible. The Bibliography listing for each text indicates the edition used, and all textual and footnote citations refer to the specified editions. When multiple editions have been consulted, the footnotes specify copytext. 
